Sir,

\section{Primary peripapillary membrane in an 8-year-old boy}

Peripapillary membranes, although rare in children, have been described secondary to other pathologies in patients as young as 5 years old. Unilateral primary cases have been described in adults but not children. We describe an apparently primary case in an otherwise well 8 year old.

\section{Case report}

An 8-year-old Caucasian boy presented to us after reduced vision in his right eye was detected at a routine optician's examination. The patient and his parents had not been aware of any change in his vision and he had no history of ocular trauma.

On examination his acuity was $6 / 36$ in the right eye and $6 / 5$ in the left with no improvement with pinhole. There was no relative afferent papillary defect or abnormalities on anterior segment examination. He was orthotropic at near and distance. Fundus examination was normal on the left. On the right there was a darkly pigmented subretinal elevation immediately temporal to the disc with an associated serous detachment of the retina. Extending to the macula was an area of pigment epithelial atrophy with exudates on its outer borders (Figure 1). The peripheral retinal vasculature was normal in both eyes and there was no evidence of past or present intraocular inflammation.

The patient had been examined by the same optician 2 years previously for a routine check. At that time the acuities were recorded as being 6/6 in both eyes. The child was otherwise well; he and his twin brother were born by elective caesarean section at term and had no other past medical history of note. The twin brother has had normal examinations recorded at his optician's on

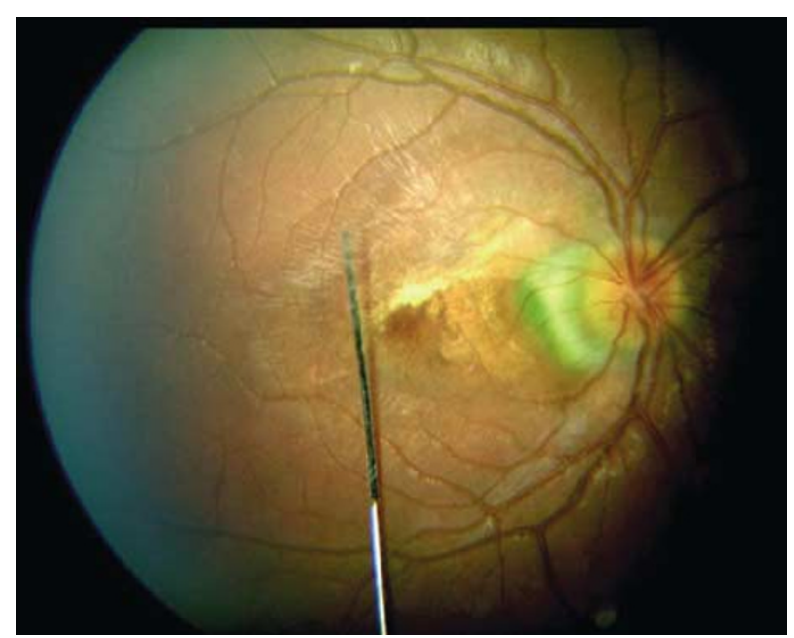

Figure 1 Right peripapillary choroidal neovascular membrane with pigment change extending to fovea and exudates superiorly. two occasions, but has not been seen by an Ophthalmologist as yet.

A fluorescein angiogram demonstrated progressive hyperfluorescence adjacent to the disc characteristic of a peripapillary choroidal neovascular membrane (Figure 2). There was no autofluorescence from the disc or linear breaks in Bruch's membrane. An ultrasound scan was also performed, which showed the pigmented mass to be homogenous and of low echogenicity, and demonstrated no foci of calcification within the optic disc (Figure 3).

As there is no active leak threatening the fovea the patient has been managed conservatively with regular follow-up.

\section{Discussion}

As well as neovascular membranes, other causes of pigmented peripapillary masses in children include

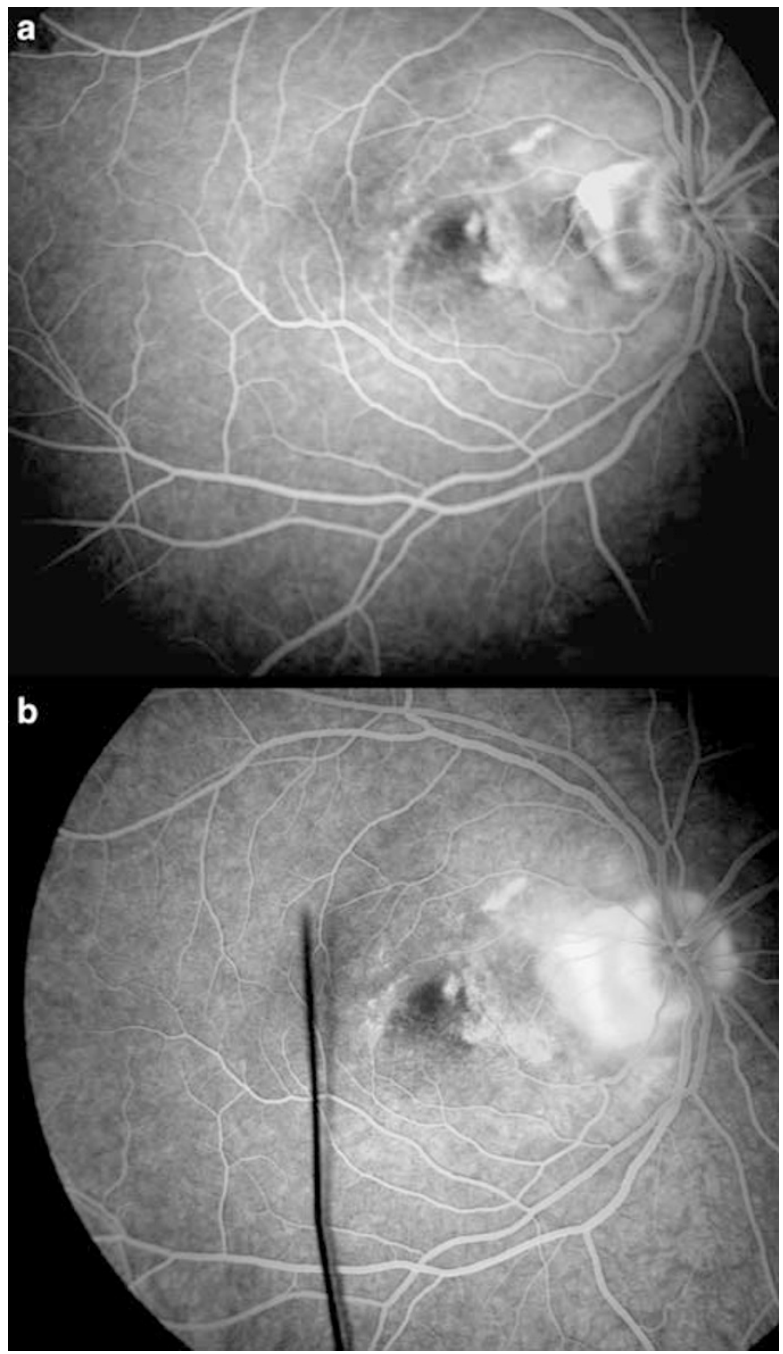

Figure 2 Fluorescein angiogram of right fundus showing increasing hyperfluorescence from the early (a) to late (b) venous pictures. 


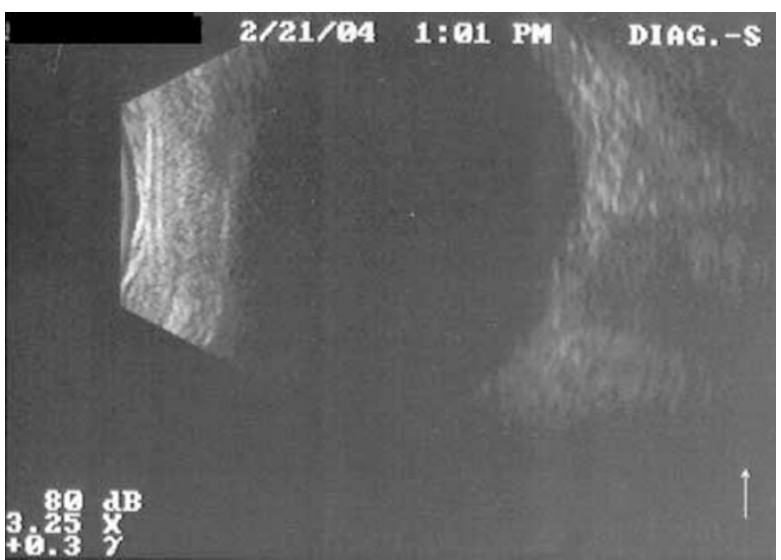

Figure 3 Ultrasound scan of right optic disc showing no evidence of disc drusen.

choroidal melanoma and CHR-RPE (combined hamartoma of the retina and retinal pigment epithelium). ${ }^{1,2}$ However, it was clear clinically in this case that the pigmented lesion was subretinal. The diagnosis of a peripapillary neovascular membrane was also supported by the ultrasound scan and fluorescein angiogram. It is likely that the neighbouring retinal pigment atrophy and exudate resulted from a more extensive macula detachment, which had since regressed spontaneously.

Most choroidal neovascular membranes are located close to the centre of the macula but peripapillary neovascular membranes represent a subset with distinct characteristics. Defects in Bruch's membrane are important in the pathophysiology of central forms of subretinal neovascularisation, but may not be necessary for peripapillary extension of choroidal neovascularisation. This is because the termination of Bruch's membrane adjacent to the disc may be sufficient alone as an entry point. ${ }^{3}$ Peripapillary neovascular membranes in adults are often secondary to conditions such as age-related macular degeneration, angioid streaks, presumed ocular histoplasmosis syndrome (POHS), myopia, optic disc drusen, trauma, chorioretinitis, and uveitis. ${ }^{4,5}$ Primary peripapillary choroidal neovascular membranes are also seen, but typically in female patients in their sixth or seventh decades. $^{5}$

In children, neovascular membranes at any location, are less common and are usually secondary to posttraumatic choroidal rupture ${ }^{6}$ or inflammatory lesions, such as toxoplasmosis, Toxocara canis, diffuse unilateral subacute neuroretinitis, rubella retinopathy, pars planitis, POHS, or chronic granulomatous disease of childhood. Less commonly choroidal neovascularisation can be seen in children with Best's vitelliform macular dystrophy or juxtafoveolar retinal telangiectasia. ${ }^{7}$ Specifically, peripapillary membranes can occur in children secondary to disc drusen ${ }^{8,9}$ and less commonly colobomas. ${ }^{10}$ However, primary membranes in children are much less common. Bilateral disciform macular detachments have been seen as isolated findings, or in children with a family history of similar lesions. ${ }^{7}$ However, a unilateral and primary peripapillary choroidal neovascular membrane has not been described previously in a child.

\section{Acknowledgements}

No grants or sponsoring organizations have been involved in the work for this submission. The authors have no proprietary or commercial interests related to the manuscript. It has not been presented previously.

\section{References}

1 Singh AD, Shields CL, Shields JA, Sato T. Uveal melanoma in young patients. Arch Ophthalmol 2000; 118: 918-923.

2 Font RL, Moura RA, Shetlar DJ, Martinez JA, McPherson AR. Combined hamartoma of sensory retina and retinal pigment epithelium. Retina 1989; 9: 302-311.

3 Jack RL. Peripapillary disciform degeneration of the retina: diagnosis and treatment. Ann Ophthalmol 1978; 15-18, 21-24, 26-31.

4 Silvestri G, Archer DB, Johnston PB. Peripapillary subretinal neovascular membranes: the natural history. Eye 1993; 7: 398-402.

5 Gass JD. Choroidal neovascular membranes - their visualization and treatment. Trans Am Acad Ophthalmol Otolaryngol 1973; 77: 310.

6 Wysznski RE, Grossniklaus HE, Frank KE. Indirect choroidal rupture secondary to blunt ocular trauma. Retina 1988; 8: 237-243.

7 Gass JD. A Stereoscopic Atlas of Macular Disease. CV Mosby Co: St. Louis, 4th ed. 1997, p 116.

8 Brown SM, Del Monte MA. Choroidal neovascular membrane associated with optic nerve head drusen in a child. Am J Ophthalmol 1996; 121: 215-217.

9 Harris MJ, Fine SL, Owens SL. Hemorrhagic complications of optic nerve drusen. Am J Ophthalmol 1981; 92: 70-76.

10 Brown GC, Tasman WS. Congenital Anomalies of the Optic Disc, Vol. 4. Grune \& Stratton: New York, NY, 1983, pp 131-141

EJ Lee, I Mavrikakis, K Fong and AG Casswell

Sussex Eye Hospital, Brighton BN2 5BF, UK

Correspondence: AG Casswell,

Tel: + 441273606126 ;

Fax: + 441273693674

E-mail: tony.casswell@bsuh.nhs.uk

Eye (2006) 20, 379-380. doi:10.1038/sj.eye.6701847;

published online 1 April 2005 